\title{
The effects of prenatal metformin on obesogenic diet-induced alterations in maternal and fetal fatty acid metabolism
}

Kemoy Harris ${ }^{1,3}$, Neeraj Desai ${ }^{1,4}$, Madhu Gupta ${ }^{2,5}$, Xiangying Xue ${ }^{5}$, Prodyot K. Chatterjee ${ }^{5}$, Burton Rochelson ${ }^{1}$ and Christine N. Metz ${ }^{1,2,5^{*}}$

\begin{abstract}
Background: Maternal obesity may program the fetus and increase the susceptibility of the offspring to adult diseases. Metformin crosses the placenta and has been associated with decreased inflammation and reversal of fatty liver in obese leptin-deficient mice. We investigated the effects of metformin on maternal and fetal lipid metabolism and hepatic inflammation using a rat model of diet-induced obesity during pregnancy.
\end{abstract}

Methods: Female Wistar rats (6-7 weeks old) were fed normal or high calorie diets for 5 weeks. After mating with normal-diet fed males, half of the high calorie-fed dams received metformin (300 mg/kg, daily); dams (8 per group) continued diets through gestational day 19. Maternal and fetal livers and fetal brains were analyzed for fatty acids and for fatty acid metabolism-related gene expression. Data were analyzed by ANOVA followed by Dunnett's post hoc testing.

Results: When compared to control-lean maternal livers, obesogenic-diet-exposed maternal livers showed significantly higher saturated fatty acids (14:0 and 16:0) and monounsaturated fatty acids (16:1n7 and 18:1n9) and lower polyunsaturated (18:2n6 and 20:4n6 [arachidonic acid]) and anti-inflammatory n3 polyunsaturated fatty acids $(18: 3 n 3$ and 22:6n3 [docosahexaenoic acid]) $(p<0.05)$. Metformin did not affect diet-induced changes in maternal livers. Fetal livers exposed to the high calorie diet showed significantly increased saturated fatty acids (18:0) and monounsaturated fatty acids (18:1n9 and 18:1n7) and decreased polyunsaturated fatty acids $(18: 2 n 6,20: 4 n 6$ and 22:6n3) and anti-inflammatory n3 polyunsaturated fatty acids, along with increased gene expression of fatty acid metabolism markers (Fasn, D5d, D6d, Scd1, Lxra). Metformin significantly attenuated diet-induced inflammation and 18:1n9 and 22:6n3 in fetal livers, as well as n3 fatty acids $(p<0.05)$. Prenatal obesogenic diet exposure significantly increased fetal liver IFNy levels $(p<0.05)$, which was reversed by maternal metformin treatment $(p<0.05)$.

Conclusions: Consumption of a high calorie diet significantly affected maternal and fetal fatty acid metabolism. It reduced anti-inflammatory polyunsaturated fatty acids in maternal and fetal livers, altered gene expression of fatty acid metabolism markers, and induced inflammation in the fetal livers. Prenatal metformin attenuated some diet-induced fatty acid changes and inflammation in the fetal livers without affecting maternal livers, suggesting that maternal metformin may impact fetal/neonatal fatty acid/lipid metabolism.

Keywords: Fatty acid metabolism, Fetal programming, Metabolic syndrome, Pregnancy

Abbreviations: AA, Arachidonic acid; DHA, Docosahexaenoic acid; FA, Fatty acid; GD, Gestational day; GDM, Gestational diabetes mellitus; HCAL, High calorie; MUFA, Monounsaturated fatty acid; PUFA, Polyunsaturated fatty acid; QPCR, Quantitative polymerase chain reaction; SFA, Saturated fatty acid

\footnotetext{
* Correspondence: cmetz@northwell.edu

${ }^{1}$ Hofstra Northwell School of Medicine, Department of OB/GYN, Division of Maternal-Fetal Medicine, Manhasset, NY, USA

${ }^{2}$ Elmezzi Graduate School of Molecular Medicine, Manhasset, NY, USA

Full list of author information is available at the end of the article
} 


\section{Background}

The prevalence of obesity and diabetes has increased in the US and globally [1-3]. Data from 2013 to 2014 reveals that over $40 \%$ of women in the US are obese $(\mathrm{BMI} \geq 30)$ and over $9 \%$ are morbidly obese $(\mathrm{BMI} \geq 40)$ - representing a linear increase since $2005[4,5]$. Pregnancy itself is characterized by increased insulin resistance, which is more severe in gestational diabetes mellitus (GDM). Maternal obesity and GDM, along with their accompanying metabolic/lipid, vascular, and inflammatory changes [6] are associated with an increased risk of poor pregnancy outcomes [7-9], as well as an increased risk of type 2 diabetes $[10,11]$ and cardiovascular disease in the future $[12,13]$. In addition, maternal obesity and aberrant glucose and lipid metabolism may program the fetus for hepatic lipid dysfunction and may increase the susceptibility of the offspring to adult diseases/ conditions, including metabolic syndrome-like phenotype and poor vascular health [14-17].

In the US, insulin has been considered the standard therapy for GDM [18]. Metformin, a biguanide drug that promotes glucose uptake and inhibits liver gluconeogenesis, is increasingly being used during pregnancy, but is not approved by the US Food and Drug Administration for use in GDM. In the absence of pregnancy, evidence for improved lipid metabolism by metformin has been accumulating $[19,20]$. In fact, metformin treatment reversed fatty liver disease in obese leptin-deficient mice [21]. Because metformin crosses the placenta [22, 23] and thus, could impact both maternal and fetal metabolism, we investigated the effects of prenatal metformin administration on maternal and fetal lipid metabolism and hepatic inflammation using a rat model of diet-induced obesity and metabolic syndrome during pregnancy.

\section{Methods}

\section{Experimental animals}

The Institutional Animal Care and Use Committee (IACUC) approved all animal studies prior to animal experimentation (\#2010-031). All animal experimentation was performed in accordance with the Public Health Service (PHS) Policy on Humane Care and Use of Laboratory Animals and euthanasia complied with the American Veterinary Medical Association (AVMA) Panel on Euthanasia. Female Wistar rats (6-7 weeks old, Taconic, Germantown, NY) were acclimatized with free access to standard rat chow and water for at least $72 \mathrm{~h}$. As previously described [24], rats were randomly assigned to one of two ad libitum diets: (1) a control rat chow or normal-fed (NORM) or (2) a high calorie diet (HCAL, consisting of $33 \%$ ground commercial rat chow, $33 \%$ full fat sweetened condensed milk, $7 \%$ sucrose, and $27 \%$ water) shown to induce GDM and metabolic syndrome in rats $[24,25]$. After 5 weeks, lean and acutely obese female rats (maintained on their respective diets) were mated with normal-fed male Wistar rats (9-14 weeks old, Taconic). On gestation day 1 (GD1), one half of the dams fed the high calorie diet received metformin $(300 \mathrm{mg} / \mathrm{kg}$, p.o. daily). All dams (NORM, $n=8$; HCAL, $n=8$; HCAL + metformin, $n=8$ ) continued their respective diets throughout gestation. On GD19 dams were euthanized by $\mathrm{CO}_{2}$ inhalation followed by exsanguination and livers were collected. Fetuses, delivered by cesarean section were euthanized by decapitation and fetal livers and brains were collected. Maternal livers, fetal livers and fetal brains were flash frozen in liquid nitrogen and stored at $-80{ }^{\circ} \mathrm{C}$.

\section{Lipid and fatty acid (FA) profiling}

Lipids were extracted from the maternal livers and fetal livers and brains according to the method of Folch-Lees [26]. Individual fatty acids (FAs) of the triglyceride fractions (maternal and fetal livers) or phospholipid fractions (fetal brains) were quantified at the Lipid Core Laboratory of Vanderbilt University's Mouse Metabolic Phenotyping Center (Grant \#DK59637), as previously described [27]. Total triglyceride-associated FAs of the maternal and fetal livers were normalized to liver weights $(\mu \mathrm{g} / \mathrm{mg})$; FA subsets and individuals FAs were expressed as percent of total fraction (mg/100 mg triglyceride-fatty acids (maternal and fetal livers) or phospholipid fatty acids (fetal brains)).

\section{Expression of markers of FA metabolism}

Markers of FA synthesis and metabolism in maternal and fetal livers and fetal brains were assessed by quantitative polymerase chain reaction (qPCR) methods, as previously described [28]. RNA was isolated using the RNeasy $^{\circ}$ Plus Universal Mini kit with DNase treatment (Qiagen, Foster City, CA); RNA samples had 260/280 and $260 / 230$ ratios $\geq 1.9$. qPCR reactions were performed (in triplicate) using rat specific primers (designed using the Roche Universal Probe Library Design Center) and synthesized by Eurofins (Huntsville, AL) for rat desaturase and elongase-related genes: D5d, D6d, Scd1, Elovl1, Elovl2, Elovl5, and Elovl6 and other genes involved in FA synthesis: Chrebp (also known as Mlxipl), Lxra, Lxrb, Srebf1, and Fasn, using the Eurogentec One Step RT qPCR mastermix (AnaSpec, Fremont, CA), 100 ng RNA, Roche Universal Library probes (Indianapolis, IN) and the Roche 480 Light Cycler, as previously described [29]. See Table 1 for qPCR primers and probes. Changes in mRNA expression (corrected using rat Hprt1 as the housekeeping gene) were calculated using the comparative $\mathrm{Ct}(\Delta \Delta \mathrm{Ct})$ method [30]. Data are presented as relative mRNA expression with the normal-fed group set to 1.0.

\section{Evaluation of cytokines and chemokines in maternal and fetal livers}

Maternal and fetal livers were analyzed for multiple cytokines using the rat 9-plex pro-inflammatory panel 
Table 1 qPCR primers used to assess gene expression of markers of lipid/fatty acid metabolism

\begin{tabular}{|c|c|c|c|}
\hline Gene & Primer & Sequence $5^{\prime}-3^{\prime}$ & $\begin{array}{l}\text { Accession number } \\
\text { (Probe number) }\end{array}$ \\
\hline Chrebp & $\begin{array}{l}\text { Forward } \\
\text { Reverse }\end{array}$ & $\begin{array}{l}\text { AATCCCAGCCCCTACACC } \\
\text { CTGGGAGGAGCCAATGTG }\end{array}$ & NM_133552.1 (10) \\
\hline$D 5 d$ & $\begin{array}{l}\text { Forward } \\
\text { Reverse }\end{array}$ & $\begin{array}{l}\text { GAACTCTCTTCTGATTGGAGAGCTA } \\
\text { CCGGAATTCATCAGTGAGC }\end{array}$ & AB052085.1 (26) \\
\hline D6d & $\begin{array}{l}\text { Forward } \\
\text { Reverse }\end{array}$ & $\begin{array}{l}\text { AATTTCCAGATTGAGCACCAC } \\
\text { AGTGGGGCAATCTTGTGC }\end{array}$ & $344.2(60)$ \\
\hline D9d & $\begin{array}{l}\text { Forward } \\
\text { Reverse }\end{array}$ & $\begin{array}{l}\text { GAAGCGAGCAACCGACAG } \\
\text { GGTGGTCGTGTAGGAACTGG }\end{array}$ & $2.2(125)$ \\
\hline Elov12 & $\begin{array}{l}\text { Forward } \\
\text { Reverse }\end{array}$ & $\begin{array}{l}\text { AACCTCGGAATCACACTTCTTा } \\
\text { TCCCAGCTGGAGAGAACG }\end{array}$ & $8.1(22)$ \\
\hline Elov15 & $\begin{array}{l}\text { Forward } \\
\text { Reverse }\end{array}$ & $\begin{array}{l}\text { TCGATGCGTCACTCAGTACC } \\
\text { CCTITGACTCGTGTGTCTCG }\end{array}$ & NM_134382.1 (122) \\
\hline lovl6 & $\begin{array}{l}\text { Forward } \\
\text { Reverse }\end{array}$ & $\begin{array}{l}\text { ATGGATGCAGGAAAACTGGA } \\
\text { GCCCGCTTGTTCATCAGA }\end{array}$ & NM_134383.2 (119) \\
\hline Fasn & $\begin{array}{l}\text { Forward } \\
\text { Reverse }\end{array}$ & $\begin{array}{l}\text { GGCCACCTCAGTCCTGTTAT } \\
\text { AGGGTCCAGCTAGAGGGTACA }\end{array}$ & NM_017332.1 (6) \\
\hline Lxra & $\begin{array}{l}\text { Forward } \\
\text { Reverse }\end{array}$ & $\begin{array}{l}\text { CAGGAAGAGATGTCCTTGTGG } \\
\text { TCTTCCACAACTCCGTTGC }\end{array}$ & NM_031627.2 (2) \\
\hline $\operatorname{Lxr} \beta$ & $\begin{array}{l}\text { Forward } \\
\text { Reverse }\end{array}$ & $\begin{array}{l}\text { AGCTCTGCCTACATCGTGGT } \\
\text { GACCCTTCTTCCGCTTGC }\end{array}$ & NM_031626.1 (106) \\
\hline Srebf & $\begin{array}{l}\text { Forward } \\
\text { Reverse }\end{array}$ & $\begin{array}{l}\text { ACAAGATTGTGGAGCTCAAGG } \\
\text { TGCGCAAGACAGCAGATTTA }\end{array}$ & NM_001276707.1 (77) \\
\hline
\end{tabular}

Forward and reverse primers for rat genes with GenBank Accession numbers and specific Roche Universal Probe numbers used for assessing mRNA expression in rat tissues by qPCR

${ }^{a}$ National Center for Biotechnology Information

(NCBI) EntrezGene (http://www.ncbi.nlm.nih.gov/gene)

assay kit (Meso Scale Diagnostics [MSD], Rockville, MD), as previously described [31]. Liver homogenates were assayed for cytokines (IFN $\gamma$, IL-1 $\beta$, IL-4, IL-5, IL-6, IL-10, IL-13, and TNF $\alpha$ ) and chemokines (CXCL1, CXC-motif ligand 1) using the MSD multiplex platform. The raw data were measured as electrochemiluminescence signals with the MSD Sector Imager 2400 plate reader (Meso Scale Diagnostics, Rockville, MD) and analyzed using the Discovery Workbench 3.0 software (MSD). The lower limits of detection for the analytes in this assay were $\leq 2 \mathrm{pg} / \mathrm{ml}$, except for: IL- $1 \beta$ (7 pg/ml), IL5 and IL-6 $(14 \mathrm{pg} / \mathrm{ml})$, and IL-10 $(20 \mathrm{pg} / \mathrm{ml})$. The $R^{2}$ value for each standard curve was between 0.99 and 1.0. Samples being compared were run on the same plate and the \% coefficient of variation of control replicates run on the same plate was between $2.3 \%$ (TNF $\alpha$ ) and $5.7 \%$ (IFN $\gamma)$. Liver cytokine data were corrected for protein concentration (Bio-Rad protein assay, Bio-Rad, Hercules, CA) and expressed as pg/g.

\section{Western blotting}

ChREBP and SREBP-1 protein expression in maternal and fetal livers was assessed by western blotting. Liver tissues (100 mg) were homogenized as described above. Proteins
(40 $\mu \mathrm{g} /$ lane, determined by BioRad protein assay) were separated by electrophoresis using Nu-PAGE ${ }^{\oplus}$ gels (Life Technologies, Grand Island, NY) and transferred to PVDF membranes (Millipore). The blots were probed with anti-SREBP-1 (Santa Cruz Biotechnology, Dallas TX), anti-ChREBP (Novus Biologicals, Littleton, CO), and antiGAPDH (Cell Signaling Technology, Danvers, MA, USA) antibodies, followed by near infrared-fluorescently labeled secondary antibodies (LI-COR, diluted 1:15,000), and revealed using the Odyssey infrared imaging system (LICOR Biosciences), as previously described [28, 32]. Band densities (SREBP-1: GAPDH and ChREBP:GAPDH) were assessed using Image J software (NIH).

\section{Statistics}

Data were analyzed using one-way ANOVAs for multiple comparisons followed by Dunnett's post-hoc testing using GraphPad Prism 5.03 (GraphPad Software, San Diego, CA). $P$ values $<0.05$ were considered significant.

\section{Results \\ High calorie diet alters maternal liver lipid profiles: no effect of metformin}

Livers obtained from the HCAL-fed dams showed a $40 \%$ increase in total triglyceride-associated FAs vs. control dam livers, irrespective of metformin treatment (Fig. 1a, $p<0.05$ ). Furthermore, maternal livers showed numerous HCAL-diet related changes in their FA profiles; HCAL-exposed livers had significantly higher saturated fatty acids (SFAs) (Fig. 1b, $p<0.05$ ) and monounsaturated fatty acids (MUFAs) (Fig. 1c, $p<0.001$ ) and lower polyunsaturated fatty acids (PUFAs) (Fig. 1d, $p<0.001$ ), as well as a 3-fold lower expression of anti-inflammatory n3 FAs compared to control-fed dams (Fig. 1e, $p<0.001$ ). More specifically, maternal HCAL livers had significantly higher 14:0, 16:0, 16:1n7, and 18:1n9 FAs and significantly lower 18:2n6, 18:3n3, 20:4n6 (arachidonic acid, AA) and 22:6n3 (docosahexaenoic acid, DHA) FAs, when compared to livers obtained from control-fed dams (Table 2). Maternal metformin treatment did not affect HCAL-diet-induced triglyceride-FA levels or FA-related changes in the maternal livers (Fig. 1a-e and Table 2).

\section{Maternal obesogenic diet affects markers of lipid metabolism in maternal livers}

Srebf1 mRNA expression was significantly induced in the maternal livers following $\mathrm{HCAL}$ diet exposure (Table 3, $p<0.001$ ). However, maternal metformin administration did not alter HCAL-induced Srebf1 mRNA expression in the maternal livers (Table 3). There were no significant changes in the mRNA expression of other markers of lipid synthesis/metabolism analyzed (Chrebp, Lxr $\alpha / \beta$, Srebf1, and Fasn, as well as various elongases 

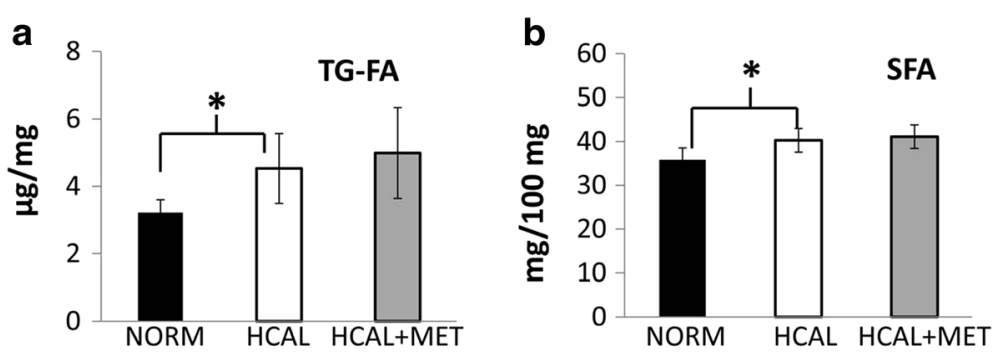

C
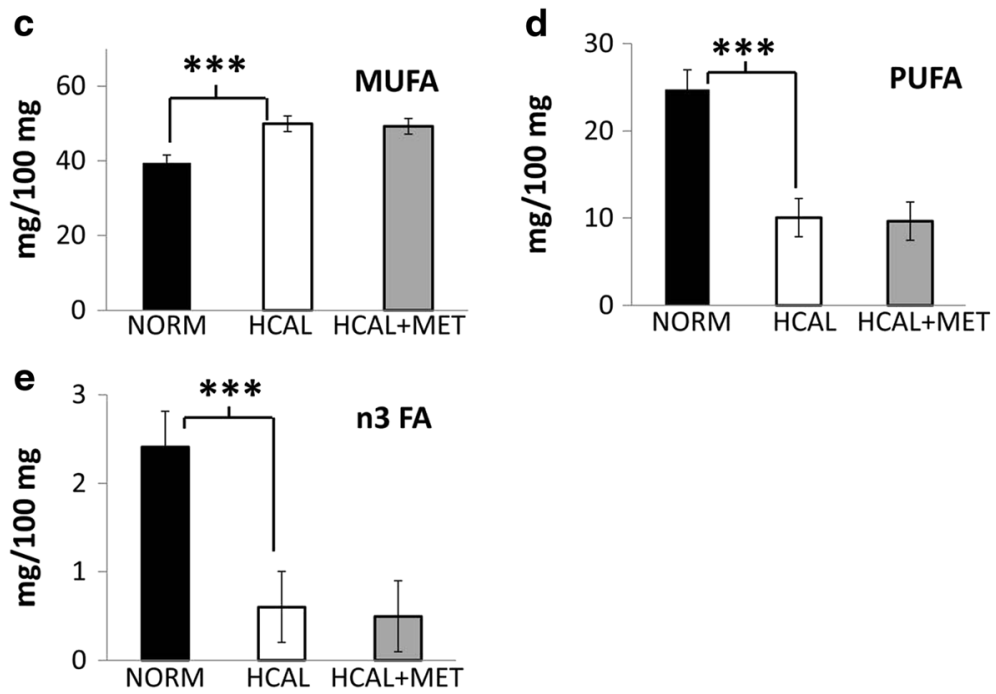

Fig. $1 \mathrm{HCAL}$ diet increases triglyceride deposition in the maternal liver and alters maternal liver lipid profiles. No effect of metformin. Dams were fed a normal (NORM) or a high calorie (HCAL) diet prior to and during pregnancy \pm metformin (MET), as described in the Methods. Maternal liver total triglyceride-associated FA (TG-FA) concentrations were determined on GD19 (a). Saturated fatty acids (SFA, b), monounsaturated FA (MUFA, c), polyunsaturated FA (PUFA, d), and n3 fatty acids (n3FA, e) profiles of the maternal livers were determined on GD19. Data are shown as mean \pm SD. ${ }^{*} p<0.05 ;{ }^{* *} p<0.01 ;{ }^{* * *} p<0.001$

Table 2 HCAL diet affects maternal liver fatty acid profiles. No effect of metformin

\begin{tabular}{lllll}
\hline Fatty acid & & $\begin{array}{l}\text { NORM mean } \\
( \pm \text { SD })\end{array}$ & $\begin{array}{l}\text { HCAL mean } \\
( \pm \text { SD })\end{array}$ & $\begin{array}{l}\text { HCAL }+ \text { MET } \\
\text { mean }( \pm \text { SD })\end{array}$ \\
\hline SFA & 14.0 & $0.6( \pm 0.14)$ & $1.3( \pm 0.24)^{\mathrm{a}^{* *}}$ & $1.2( \pm 0.20)$ \\
& 16.0 & $28.5( \pm 1.90)$ & $32.7( \pm 2.35)^{\mathrm{a}^{*}}$ & $33.4( \pm 2.25)$ \\
& 18.0 & $6.7( \pm 0.44)$ & $6.3( \pm 1.89)$ & $6.5( \pm 0.60)$ \\
MUFA & $16.1 \mathrm{n} 7$ & $2.1( \pm 0.47)$ & $4.2( \pm 0.89)^{\mathrm{a}^{*}}$ & $3.7( \pm 0.47)$ \\
& $18.1 \mathrm{n} 9$ & $33.2( \pm 1.43)$ & $41.4( \pm 1.04)^{\mathrm{a}^{*}}$ & $41.3( \pm 1.79)$ \\
& $18.1 \mathrm{n} 7$ & $4.1( \pm 0.29)$ & $4.4( \pm 0.44)$ & $4.2( \pm 0.74)$ \\
PUFA & $18.2 \mathrm{n} 6$ & $19.5( \pm 2.60)$ & $8.3( \pm 1.41)^{\mathrm{a}^{*}}$ & $8.1( \pm 1.10)$ \\
& $18.3 \mathrm{n} 3$ & $0.8( \pm 0.10)$ & $0.3( \pm 0.19)^{\mathrm{a}^{*}}$ & $0.2( \pm 0.21)$ \\
& $20.4 \mathrm{n} 6$ & $2.6( \pm 0.74)$ & $1.1( \pm 0.34)^{\mathrm{a}^{*}}$ & $1.1( \pm 0.39)$ \\
& $22.6 \mathrm{n} 3$ & $1.6( \pm 0.63)$ & $0.3( \pm 0.23)^{\mathrm{a}^{*}}$ & $0.2( \pm 0.22)$ \\
\hline
\end{tabular}

NORM normal diet, HCAL high calorie diet, MET metformin, SD standard deviation, SFA saturated fatty acids, MUFA monounsaturated fatty acids, PUFA polyunsaturated fatty acids

${ }^{a}$ NORM vs. HCAL; ${ }^{*} p<0.05, * * p<0.01$

Data are expressed as mean \pm SD $(\mathrm{mg} / 100 \mathrm{mg})$
(Elovl2, 5, or 6) and desaturases (D5d, D6d, D9d [Scd1])) in the maternal livers following the HCAL diet ( \pm metformin) (Table 3). Next, we confirmed the increased expression of SREBP-1 protein in maternal livers following HCAL diet exposure when compared to controls (Fig. 2a and b, $p<0.001)$; the increased SREBP-1 protein expression was partially attenuated by metformin administration (Fig. 2a and b, $p<0.05$ ). By contrast, maternal liver ChREBP protein expression was unaffected by HCALdiet exposure ( \pm metformin) (Fig. 2a and b).

\section{HCAL diet prior to and during pregnancy did not} promote cytokine production in maternal livers

Based on the link between hepatic liver lipid accumulation and inflammation, we assessed maternal livers obtained from control-fed and HCAL-fed ( \pm metformin) dams for numerous cytokines. We found no effect of the HCAL diet (with or without metformin) on localized hepatic inflammation, as determined by measuring IL- $1 \beta$, IL-4, IL-5, IL-6, IL-10, IL-13, IFN $\gamma$, TNF $\alpha$, and CXCL1 concentrations in the maternal livers (Additional file 1: Table S1). 
Table 3 The effects of high calorie diet ( \pm metformin) on gene expression in maternal and fetal livers

\begin{tabular}{|c|c|c|c|c|c|c|}
\hline \multicolumn{4}{|c|}{ Maternal livers } & \multicolumn{3}{|l|}{ Fetal Livers } \\
\hline Gene & NORM mean $( \pm S D)$ & HCAL mean $( \pm S D)$ & $\overline{\mathrm{HCAL}}+\mathrm{MET}$ mean $( \pm \mathrm{SD})$ & $\overline{\text { NORM mean }( \pm S D)}$ & HCAL mean $( \pm S D)$ & $\mathrm{HCAL}+\mathrm{MET}$ mean $( \pm \mathrm{SD})$ \\
\hline Chrebp & $1.0( \pm 0.33)$ & $0.9( \pm 0.19)$ & $1.1( \pm 0.41)$ & $1.0( \pm 0.25)$ & $1.1( \pm 0.34)$ & $0.9( \pm 0.46)$ \\
\hline D5d & $1.0( \pm 0.36)$ & $1.2( \pm 0.23)$ & $1.4( \pm 0.27)$ & $1.0( \pm 0.34)$ & $1.5( \pm 0.44)^{\mathrm{a}^{*}}$ & $1.4( \pm 0.34)$ \\
\hline D6d & $1.0( \pm 0.49)$ & $1.1( \pm 0.33)$ & $1.5( \pm 0.26)$ & $1.0( \pm 0.31)$ & $1.5( \pm 0.23)^{\mathrm{a}^{* * *}}$ & $1.6( \pm 0.26)$ \\
\hline D9d (Scd1) & $1.0( \pm 0.68)$ & $1.2( \pm 0.35)$ & $1.3( \pm 0.33)$ & $1.0( \pm 0.33)$ & $1.4( \pm 0.37)^{a^{*}}$ & $1.2( \pm 0.28)$ \\
\hline Elovl2 & $1.0( \pm 0.39)$ & $0.9( \pm 0.24)$ & $0.8( \pm 0.13)$ & $1.0( \pm 0.23)$ & $1.1( \pm 0.30)$ & $1.0( \pm 0.32)$ \\
\hline Elovl5 & $1.0( \pm 0.14)$ & $1.0( \pm 0.24)$ & $1.1( \pm 0.06)$ & $1.0( \pm 0.12)$ & $1.5( \pm 0.86)$ & $1.1( \pm 0.18)$ \\
\hline Elovl6 & $1.0( \pm 0.37)$ & $0.8( \pm 0.26)$ & $1.0( \pm 0.43)$ & $1.0( \pm 0.15)$ & $1.1( \pm 0.16)$ & $1.3( \pm 0.25)$ \\
\hline Fasn & $1.0( \pm 0.46)$ & $1.0( \pm 0.47)$ & $1.1( \pm 0.39)$ & $1.0( \pm 0.18)$ & $1.5( \pm 0.28)^{\mathrm{a}^{* * *}}$ & $1.6( \pm 0.37)$ \\
\hline Lxra & $1.0( \pm 0.13)$ & $1.0( \pm 0.09)$ & $1.1( \pm 0.14)$ & $1.0( \pm 0.13)$ & $1.2( \pm 0.30)^{\mathrm{a}^{* *}}$ & $1.3( \pm 0.30)$ \\
\hline$L x r \beta$ & $1.0( \pm 0.42)$ & $1.0( \pm 0.11)$ & $1.0( \pm 0.13)$ & $1.0( \pm 0.13)$ & $1.0( \pm 0.14)$ & $1.0( \pm 0.13)$ \\
\hline Srebfi & $1.0( \pm 0.29)$ & $1.8( \pm 0.36)^{\mathrm{a}^{* * *}}$ & $1.7( \pm 0.38)$ & $1.0( \pm 0.23)$ & $1.3( \pm 0.40)$ & $1.2( \pm 0.19)$ \\
\hline
\end{tabular}

NORM normal diet, HCAL high calorie diet, MET metformin, SD standard deviation

${ }^{a}$ NORM vs. HCAL; ${ }^{*} p=<0.05 ;{ }^{* *} p<0.01,{ }^{* * *} p<0.001$

Data are presented as relative mRNA expression (mean $\pm \mathrm{SD}$ ), with the normal-fed group set to 1.0

Fetal exposure to maternal obesity significantly alters fetal hepatic FA profile; metformin reverses some of these effects

Although in utero exposure to the HCAL diet did not significantly change the total triglyceride-associated FA content of the fetal livers on embryonic day 19 (Fig. 3a), it significantly increased SFAs (Fig. $3 \mathrm{~b}, p<0.01$ ) and MUFAs (Fig. 3c, $p<0.001$ ), and significantly decreased PUFAs (Fig. 3d, $p<0.001$ ), as well as anti-inflammatory n3 FAs when compared to control fetal livers (Fig. 3e, $p<0.001)$. More specifically, livers obtained from HCAL diet-exposed fetuses showed significantly increased 18:0, 18:1n9, and 18:1n7 and significantly reduced 18:2n6, 20:4n6 (AA), and 22:6n3 (DHA) (Table 4). While no changes in maternal hepatic FA profiles were observed following metformin administration (Fig. 1b-e and Table 2), significant changes in diet-induced FA changes in the fetal livers were observed following maternal metformin treatment. HCALinduced overall MUFAs (Fig. 3c, $p<0.001$ ), specifically $18: 1 n 9$, were significantly attenuated by maternal metformin administration (Table $4, p<0.01$ ), while HCALinduced $18: 1 \mathrm{n} 7$ was only slightly reduced (not significant) (Table 4). Maternal metformin blocked HCAL-reduced 22:6n3 (DHA) in fetal livers following HCAL-exposure (Table 4, $p<0.05$ ). Similarly, HCAL-suppressed n3 FA levels in the fetal livers were reversed by maternal metformin treatment (Fig. 3e, $p<0.001$ ).

In utero exposure to maternal high calorie diet alters markers of lipid metabolism in fetal livers

Fetal exposure to the maternal HCAL-diet significantly increased the expression of several genes shown to be involved in fatty acid metabolism in the fetal livers, including D5d, D6d, D9d [Scd1], Fasn, and Lxra (Table 3).
In utero metformin exposure did not significantly attenuate these effects; however, metformin slightly (not significantly) reduced the effects of HCAL diet exposure on $D 5 d$ and $D 9 d(S c d 1)$ mRNA expression in fetal livers when assessed on embryonic day 19 (Table 3). Western blotting of fetal livers confirmed that neither SREBP-1 nor ChREBP protein expression was affected by HCAL diet (with or without metformin) (Fig. 4a-b).

\section{In utero exposure to maternal obesogenic diet} significantly affects fetal brain FA profiles

While fetal brains had no significant differences in overall phospholipid-associated SFA, MUFA, PUFA, or n3 FA concentrations following HCAL-diet exposure when compared to controls (Fig. 5a-d), HCAL diet-exposed fetal brains had significantly reduced 20:4n6 (AA), 22:4n6, and 22:5n6 and significantly increased 22:6n3 (DHA) concentrations when compared to controls (Table 5). With the exception of HCAL-reduced 22:5n6 in the fetal brains, which was reversed by maternal metformin treatment $(p<0.05)$, no other changes were observed following maternal metformin administration (Table 5). Fetal exposure to the HCAL-diet reduced $D 9 d(S c d 1)$ mRNA expression in the fetal brains (Table 6, $p<0.05$ ), but maternal metformin had no effect on $D 9 d(S c d 1)$ mRNA expression (Table 6).

\section{Prenatal exposure to metformin reduces HCAL diet- induced IFN $\gamma$ levels in fetal livers}

Although no effect of the HCAL diet was found on maternal liver inflammation, as assessed by measuring various cytokines and chemokines (see Additional file 1: Table S1), in utero exposure to the maternal obesogenic diet significantly increased IFN $\gamma$ concentrations in the 


\section{a \\ Maternal Liver}

HCAL HCAL HCAL NORM NORM NORM HCAL HCAL HCAL MET MET MET
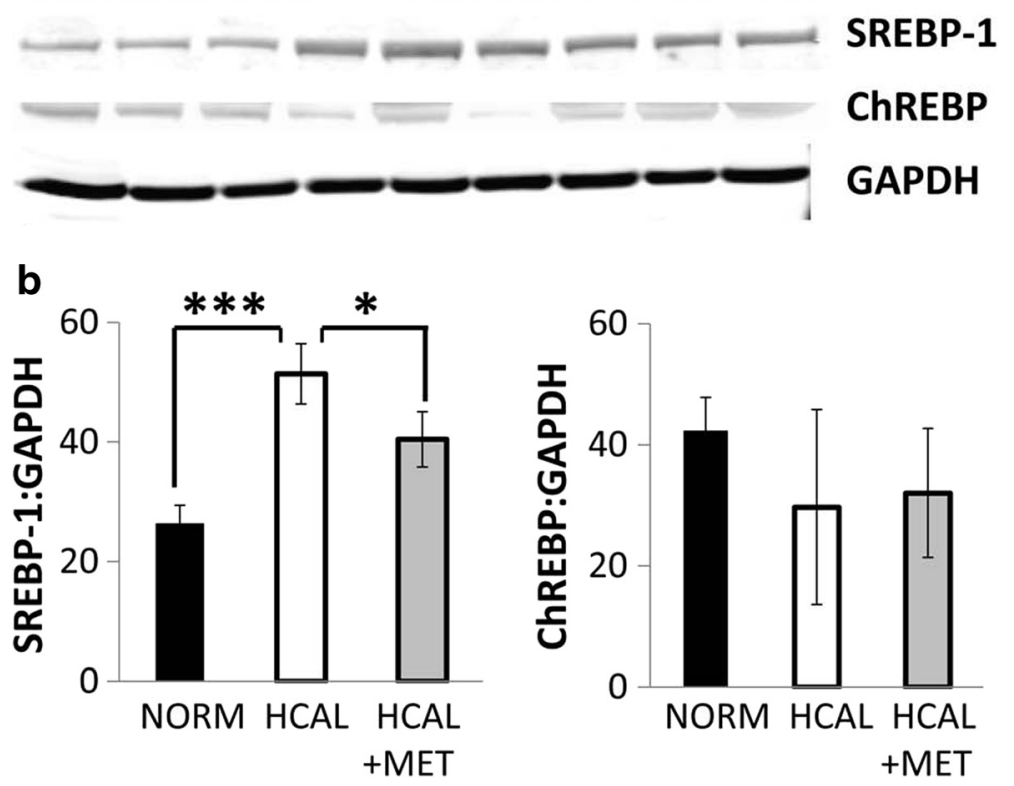

Fig. 2 SREBP-1 protein in the maternal liver is increased by the HCAL diet. Maternal livers obtained from dams after feeding normal (NORM) or high calorie (HCAL) diets ( \pm metformin, MET) were examined on GD19 for SREBP-1 and ChREBP protein expression by western blotting (a). Quantitation of SREBP-1 and ChREBP bands normalized for GAPDH expression (SREBP-1:GAPDH and ChREBP:GAPDH) is shown in $\mathbf{b}$. Data are shown as mean \pm SD. ${ }^{*} p<0.05 ;{ }^{* * *} p<0.001$

fetal livers (Fig. 6 and Additional file 1: Table S1). This effect was attenuated by prenatal metformin exposure (Fig. 6 and Additional file 1: Table S1).

\section{Discussion}

Obesity in pregnant women is accompanied by dyslipidemia, characterized by elevated triglyceride levels [6] Consumption of the HCAL diet enriched in saturated fats and sugar by pregnant rats significantly increased total triglycerides and increased proportion of SFAs, and MUFAs, and decreased PUFAs and n3 FAs in maternal rat livers (Fig. 1 and Table 2). The most notable changes in the maternal livers were the $>2$-fold decline in PUFAs (Fig. 1d) and the 3-fold decline in anti-inflammatory $n 3$ FAs (Fig. 1e). These changes might be detrimental, as maternal PUFAs are essential for healthy fetal development, including the fetal brain [33] and because n3 FAs have been proposed to regulate fetal brain development [34] and improve insulin resistance during pregnancy [35]. Likewise, the accumulation of the end product of de novo lipogenesis, 18:1n9 (oleic acid), was significantly higher in the HCAL-exposed maternal livers when compared to control maternal livers (Table 2). These changes, indicative of liver dysfunction and enhanced de novo lipogenesis, were accompanied by elevated Srebf mRNA expression (almost 2fold, Table 3) and increased SREBP-1 protein (Fig. 2a-b) in the maternal livers following the obesogenic diet. SREBP-1 serves as one of the major regulators of de novo lipogenesis/fatty acid synthesis by activating genes required for lipogenesis [36, 37]. In fact, overexpression of SREBP-1 in transgenic mice produced fatty livers via excess de novo lipogenesis [38]. Hepatic triglyceride deposition and metabolic syndrome have been strongly associated with insulin resistance $[39,40]$. Both insulin and glucose are the major inducers of Srebf mRNA expression, and thus, these results are consistent with previous studies showing that this obesogenic diet induces GDM [25] and metabolic syndrome, as determined by increased maternal circulating insulin, leptin, and triglyceride levels [24].

Maternal obesity and metabolic syndrome can lead to adverse fetal outcomes, including structural anomalies and fetal liver lipotoxicity $[41,42]$. Fetal exposure to excess maternal lipids and their metabolites are proposed to trigger signaling pathways in developing organs, including the liver, adipose, skeletal muscle, and brain, that lead to shortand long-term metabolic consequences (e.g., energy storage, cell differentiation, cell death, and inflammation) (Reviewed in [41]). We found that in utero HCAL exposure did not affect total triglyceride-associated fatty acids in the fetal livers, but it significantly increased the proportion of SFAs and MUFAs, decreased PUFAs and n3 FAs (Fig. 3b-e and Table 4), and elevated IFNY in the fetal 

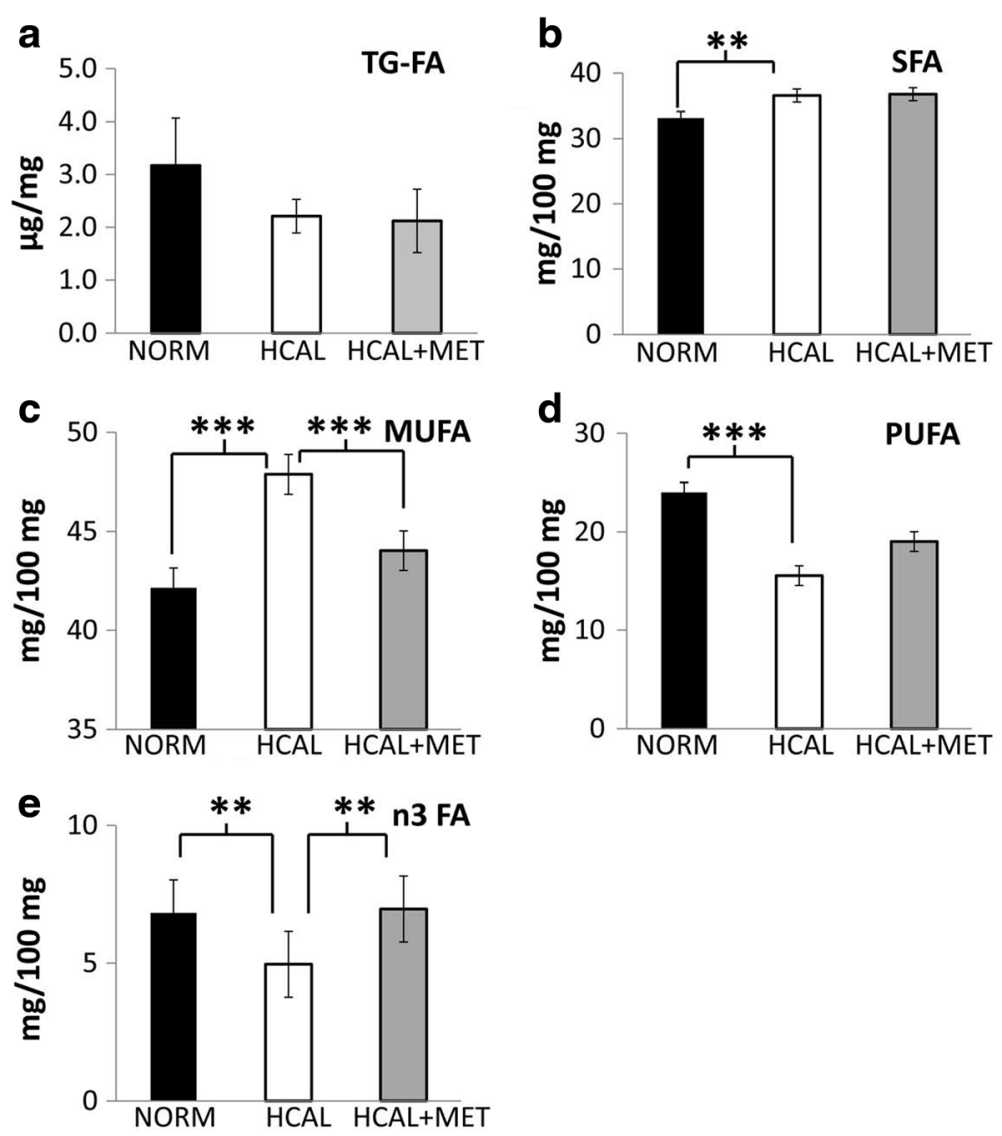

Fig. 3 HCAL diet exposure alters fetal liver fatty acid profiles. Modifications by in utero metformin exposure. Fetuses were exposed to either a normal (NORM) or a high calorie (HCAL) maternal diet ( \pm metformin, MET), as described in the Methods. Fetal liver total triglyceride-associated fatty acid (TG-FA) concentrations (a), saturated fatty acids (SFA, b), monounsaturated FA (MUFA, c), polyunsaturated FA (PUFA, d), and n3 FA (e) profiles of the fetal livers were determined on embryonic day 19. Data are shown as mean \pm SD.* $p<0.05 ;{ }^{* * *} p<0.001$

Table 4 HCAL diet ( \pm metformin) exposure alters FA profiles of fetal livers

\begin{tabular}{lllll}
\hline Fatty acid & & NORM mean $( \pm$ SD $)$ & HCAL mean $( \pm S D)$ & HCAL + MET mean $( \pm$ SD $)$ \\
\hline SFA & 14.0 & $2.1( \pm 0.18)$ & $2.2( \pm 0.27)$ & $2.1( \pm 0.23)$ \\
& 16.0 & $23.9( \pm 0.96)$ & $25.6( \pm 1.57)$ & $9.2( \pm 0.76)$ \\
MUFA & $7.18( \pm 0.73)$ & $8.8( \pm 0.87)^{a^{* * *}}$ & $3.9( \pm 0.29)$ \\
& $16.1 \mathrm{n} 7$ & $4.3( \pm 0.45)$ & $4.6( \pm 0.46)$ & $35.9( \pm 2.26)^{b^{* *}}$ \\
& $18.1 \mathrm{n} 9$ & $34.2( \pm 1.56)$ & $38.8( \pm 2.08)^{\mathrm{a}^{* *}}$ & $4.2( \pm 0.17)$ \\
PUFA & $18.1 \mathrm{n} 7$ & $3.6( \pm 0.28)$ & $4.4( \pm 0.20)^{\mathrm{a}^{* * *}}$ & $10.1( \pm 0.92)$ \\
& $18.2 \mathrm{n} 6$ & $14.4( \pm 2.1)$ & $8.8( \pm 1.70)^{\mathrm{a}^{* * *}}$ & $0.22( \pm 0.28)$ \\
& $18.3 \mathrm{n} 6$ & $0.5( \pm 0.26)$ & $0.4( \pm 0.21)$ & $1.7( \pm 0.31)$ \\
& $20.4 \mathrm{n} 6$ & $2.2( \pm 0.69)$ & $1.4( \pm 0.43)^{\mathrm{a}^{*}}$ & $7.0( \pm 1.21)^{\mathrm{b}^{*}}$ \\
\hline
\end{tabular}

NORM normal diet, HCAL high calorie diet, MET metformin, SD standard deviation, SFA saturated fatty acids, MUFA monounsaturated fatty acids, PUFA polyunsaturated fatty acids

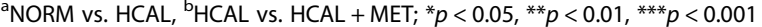

Data are expressed as mean \pm SD $(\mathrm{mg} / 100 \mathrm{mg})$ 
a

\section{Fetal Liver}

HCAL HCAL HCAL NORM NORM NORM HCAL HCAL HCAL MET MET MET
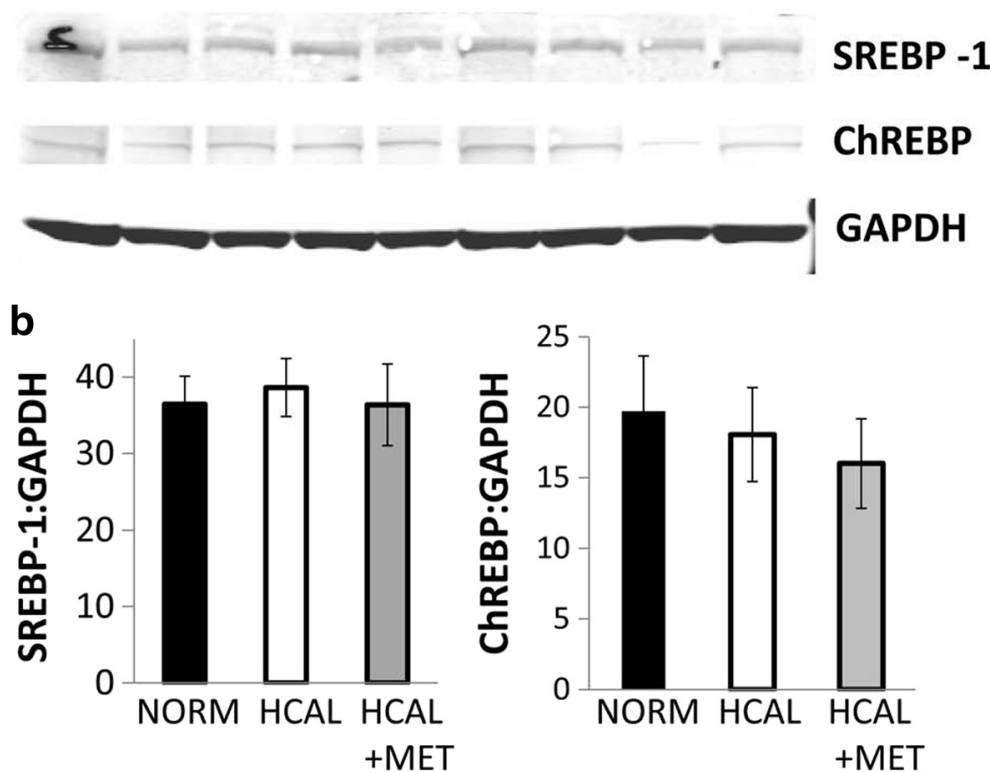

Fig. 4 SREBP-1 and ChREBP protein expression in the fetal livers are unaffected by exposure to the HCAL diet. No effect of metformin. Fetal livers were examined for SREBP-1 and ChREBP protein expression by western blotting (a). Quantitation of SREBP-1 and ChREBP bands normalized for GAPDH expression (SREBP-1:GAPDH and ChREBP:GAPDH) are shown in $\mathbf{b}$
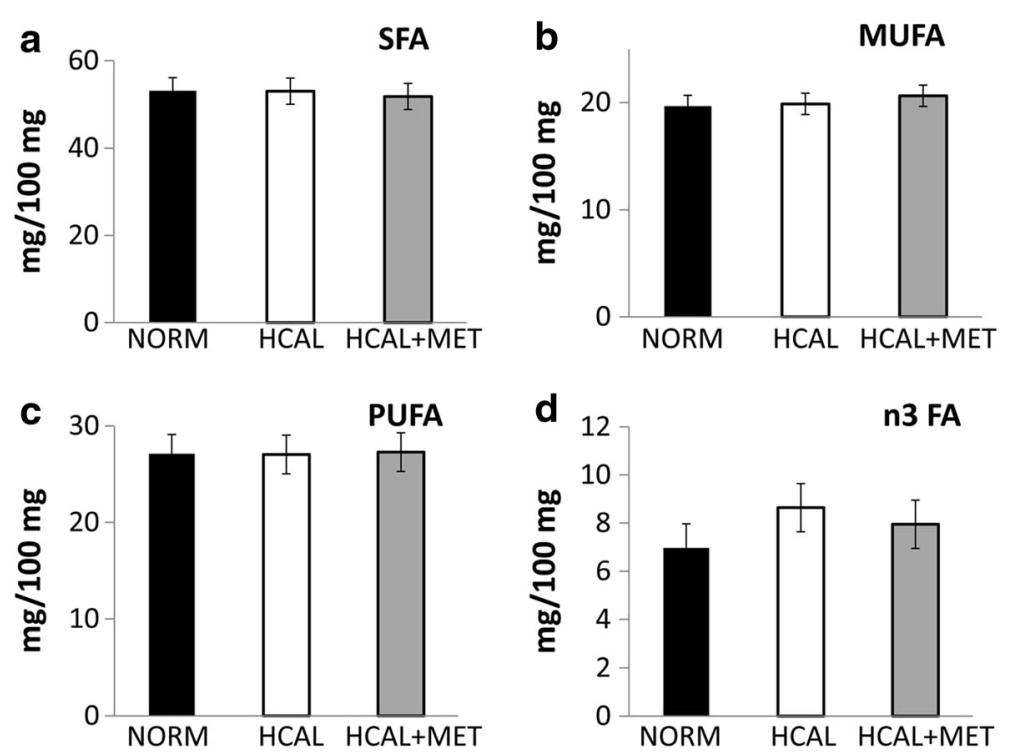

Fig. 5 Effect of HCAL diet exposure on fetal brain fatty acid profiles. No effect of metformin. Fetuses were exposed to either a normal (NORM) or a high calorie (HCAL) maternal diet ( \pm metformin, MET), as described in the Methods. The saturated fatty acids (SFA, a), monounsaturated FA (MUFA, b), polyunsaturated FA (PUFA, c), and n3 FA (d) profiles of the fetal brains were determined on embryonic day 19. Data are shown as mean \pm SD 
Table 5 Effects of maternal HCAL diet ( \pm metformin) on fetal brain FA profiles

\begin{tabular}{lllll}
\hline Fatty acid & & NORM mean $( \pm$ SD $)$ & HCAL mean $( \pm$ SD $)$ & HCAL + MET mean $( \pm$ SD $)$ \\
\hline SFA & 14.0 & $1.9( \pm 0.08)$ & $2.0( \pm 0.05)$ & $2.0( \pm 0.23)$ \\
& 16.0 & $33.4( \pm 0.89)$ & $33.6( \pm 0.93)$ & $32.8( \pm 0.27)$ \\
MUFA & 18.0 & $17.8( \pm 0.81)$ & $17.5( \pm 0.52)$ & $16.9( \pm 0.30)$ \\
& $16.1 n 7$ & $2.2( \pm 0.21)$ & $2.2( \pm 0.10)$ & $2.3( \pm 0.12)$ \\
& $18.1 n 9$ & $13.6( \pm 0.56)$ & $13.9( \pm 0.30)$ & $14.3( \pm 0.39)$ \\
PUFA & $18.1 \mathrm{n} 7$ & $3.9( \pm 0.19)$ & $3.9( \pm 0.26)$ & $1.0( \pm 0.21)$ \\
& $20.4 n 6$ & $13.2( \pm 0.42)$ & $12.5( \pm 0.35)^{\mathrm{a}^{*}}$ & $3.0( \pm 0.41)$ \\
& $22.4 \mathrm{n} 6$ & $3.2( \pm 0.12)$ & $2.9( \pm 0.03)^{\mathrm{a}^{* *}}$ & $3.0( \pm 0.17)$ \\
& $22.5 \mathrm{n} 6$ & $2.9( \pm 0.24)$ & $2.3( \pm 0.22)^{\mathrm{a}^{* *}}$ & $2.7( \pm 0.22)^{\mathrm{b}^{*}}$ \\
\end{tabular}

NORM normal diet, HCAL high calorie diet, MET metformin, SD standard deviation, SFA saturated fatty acids, MUFA monounsaturated fatty acids, PUFA polyunsaturated fatty acids

${ }^{\mathrm{a}} \mathrm{NORM}$ vs. HCAL, ${ }^{\mathrm{b}} \mathrm{HCAL}$ vs. HCAL $+\mathrm{MET} ;{ }^{*} p<0.05,{ }^{* *} p<0.01$

Data are expressed as mean \pm SD $(\mathrm{mg} / 100 \mathrm{mg})$

livers (Fig. 6). IFN $\gamma$, previously shown to accompany hepatic steatosis in mice [43], may directly induce endoplasmic reticulum stress, a potential contributor to the vicious cycle of obesity and chronic inflammation [35]. HCAL diet-exposed fetal livers showed enhanced Lxra mRNA expression (Table 3). $L x r \alpha$ is considered the master regulator of hepatic lipogenesis; it induces Fasn [36, 37]. We observed enhanced Fasn, D5d, D6d, and D9d mRNA expression in the HCAL-exposed fetal livers (Table 3), consistent with previous studies showing altered FA metabolism and lipid accumulation in the fetal livers of non-human primates following exposure to a chronic maternal high fat diet [42].

Aberrant FA profiles found in the fetal brains following in utero HCAL-diet exposure (decreased 20:4n6,

Table 6 The effects of HCAL diet ( \pm metformin) on gene expression in fetal brains

\begin{tabular}{llll}
\hline Gene & $\begin{array}{l}\text { NORM mean } \\
( \pm \text { SD })\end{array}$ & $\begin{array}{l}\text { HCAL mean } \\
( \pm S D)\end{array}$ & $\begin{array}{l}\text { HCAL }+ \text { MET } \\
\text { mean }( \pm S D)\end{array}$ \\
\hline Chrebp & ND & ND & ND \\
D5d & $1.0( \pm 0.14)$ & $0.9( \pm 0.13)$ & $1.0( \pm 0.19)$ \\
D6d & $1.0( \pm 0.06)$ & $0.9( \pm 0.12)$ & $1.1( \pm 0.09)$ \\
D9d $(S c d 1)$ & $1.0( \pm 0.06)$ & $0.9( \pm 0.11)^{\mathrm{a}^{* * *}}$ & $0.8( \pm 0.05)$ \\
Elov12 & $1.0( \pm 0.10)$ & $1.4( \pm 0.42)$ & $1.5( \pm 0.08)$ \\
Elov15 & $1.0( \pm 0.20)$ & $1.0( \pm 0.14)$ & $1.0( \pm 0.10)$ \\
Elovl6 & $1.0( \pm 0.15)$ & $0.9( \pm 0.17)$ & $1.1( \pm 0.16)$ \\
Fasn & $1.0( \pm 0.13)$ & $1.0( \pm 0.07)$ & $1.0( \pm 0.10)$ \\
Lxra & $1.0( \pm 0.01)$ & $1.2( \pm 0.07)$ & $1.4( \pm 0.29)$ \\
Lxrß & $1.0( \pm 0.19)$ & $0.9( \pm 0.09)$ & $0.8( \pm 0.22)$ \\
Srebf1 & $1.0( \pm 0.14)$ & $1.1( \pm 0.23)$ & $1.0( \pm 0.27)$
\end{tabular}

NORM normal diet, HCAL high calorie diet, MET metformin, SD standard deviation ${ }^{a}$ NORM vs. HCAL; ${ }^{* * *} p<0.001$

Data are presented as relative mRNA expression (mean \pm SD), with the normal-fed group set to 1.0 22:4n6, and 22:5n6 (PUFAs), Table 5) were consistent with decreased PUFAs in the maternal and fetal livers (Figs. 1 and 3, Tables 2 and 4). Surprisingly, fetal brains exposed to the HCAL diet showed increased 22:6n3 (DHA) (Table 5). DHA, which is primarily obtained via transplacental transport from the maternal side, is critically important for fetal brain development [33]. Maternal liver DHA levels were more reduced by the HCAL diet when compared to those in the fetal liver. Thus, the observed increase in fetal brain DHA levels may represent a fetal compensatory mechanism to obtain DHA from the maternal compartment to protect the fetal brain despite reduced DHA availability and reduced fetal liver DHA levels.

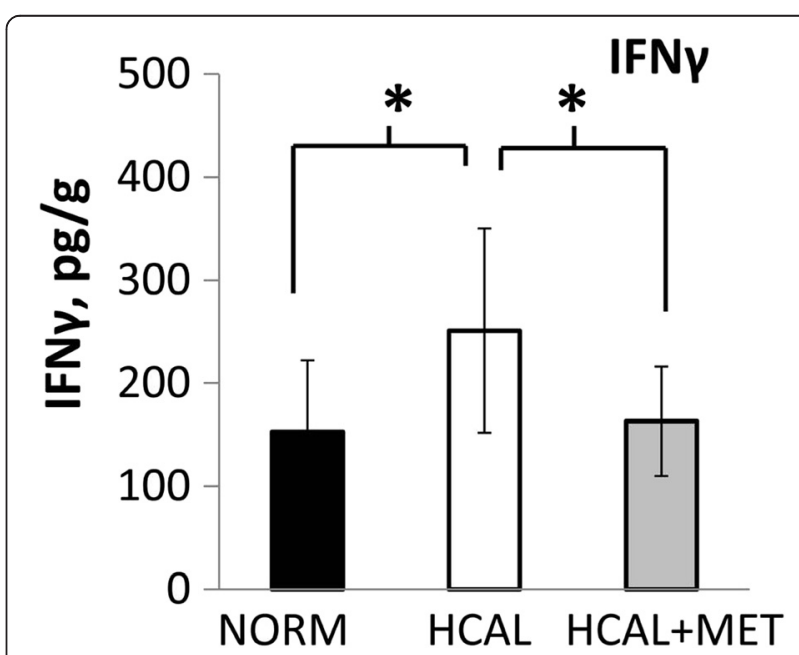

Fig. 6 Intrauterine exposure to HCAL diet increases fetal liver IFNY levels. Metformin attenuates enhanced IFNy levels in fetal livers. Fetal livers were obtained following exposure to maternal normal (NORM) or high calorie (HCAL) diets ( \pm metformin, MET) on embryonic day 19 and IFNy levels were assessed and adjusted for fetal liver protein concentration; data are shown as mean \pm SD. ${ }^{*} p<0.05$ 
Aberrant liver lipid metabolism and fatty liver disease are significant contributors to the morbidity and mortality associated with obesity-related diabetes [44]. Treating gestational diabetics through diet modification, exercise, and drugs (e.g., insulin and oral anti-diabetic agents, including metformin) improves maternal, fetal/neonatal, and offspring outcomes [45]. In the non-pregnant state, metformin enhances glucose regulation and lipid metabolism in obese women $[19,46]$ and diabetic/hyperinsulinemic rodents [20,47]. Although it has been safely used for treating GDM in other countries since the 1970s [48], metformin has only been regularly prescribed to women with GDM in the US within recent years [49]. Similarly, treatment of GDM with metformin has recently increased in Norway, Wales, and the rest of the UK [50]. Evidence from randomized controlled trials and observational studies revealing no adverse maternal or fetal/neonatal effects in the short-term [51, 52] supports using metformin for GDM [18]. The 2013 MiG trial comparing insulin vs. metformin for treating gestational diabetics confirmed the safety of metformin in pregnancy and revealed no differences in either maternal circulating hormones/metabolites, birth weight, or neonatal anthropometric measurements between the two treatments [53]. The results of the MiG trial showed only subtle effects of metformin on maternal lipid parameters associated with cardiovascular risk and no effects on cord blood (fetal) lipids [53]. However, invasive antenatal lipid analyses, as reported herein, were not performed.

Metformin improves hepatic lipid metabolism [19, 20]. In the non-pregnant state, metformin reverses fatty liver disease in obese leptin-deficient mice [21], blocks hepatic steatosis, liver inflammation, and fibrosis in a non-diabetic nonalcoholic steatohepatitis (NASH) mouse model [54], and counter-regulates diet-induced SREBP-1 and fatty acid synthase (FASN) protein expression in a mouse model [55]. Although maternal metformin administration reversed HCAL diet-induced SREBP-1 protein expression in maternal livers (Fig. 2), it had no effect on HCALinduced hepatic (total) triglyceride-associated FA levels (Fig. 1a), fatty acid profile changes (Fig. 1b-e and Table 2) or FA-related gene expression in maternal livers (Table 3). In fact, metformin slightly increased total triglycerideassociated FA levels in the maternal rat liver, a finding that is consistent with the reported increase in circulating triglyceride levels and atherogenic plasma values in women with GDM who were treated with metformin vs. insulin later in pregnancy [56]. These results suggest potentially differential regulation of FA metabolism by metformin in the pregnant and non-pregnant states. Alternatively, in our study HCAL diet-induced changes in the maternal liver might not have been significant enough to be modified by metformin, a higher dose of metformin might be required in pregnancy, or the duration of metformin treatment was too short to observe measurable changes. However, this same HCAL diet regimen induced both GDM [25] and hyperinsulinemia [24] in pregnant rats.

Prenatal metformin exposure may affect the fetal compartment and lead to long-term programming effects on fetal metabolism [57], which may be positive. We and others have shown that maternal metformin exerts antiinflammatory effects $[24,54,58,59]$, including the reduction of cytokines/chemokines in the fetal plasma and amniotic fluid in a rat model of diet-induced obesity/ metabolic syndrome [24]. Although we did not observe significant HCAL-induced maternal liver-associated inflammation, elevated IFN $\gamma$ concentrations were found in the fetal livers, and these were attenuated by maternal metformin administration (Fig. 6). Consistent with the fetal programming effects of metformin, in utero metformin exposure reversed diet-induced overall MUFA (Fig. 3c), as well as HCAL-diet reduced n3 FA (Fig. 3e), 18:1n9 (oleic acid) levels, and 22:6n3 (DHA) levels in fetal livers (Table 4). Although not significant, metformin slightly attenuated HCAL-induced D5d and D9d mRNA expression in the fetal livers (Table 3). By contrast, except for 22:5n6 (a minor phospholipid-fatty acid in the brain), in utero metformin exposure had no effects on diet-induced FA changes in the fetal brains (Table 5).

Our data show significant effects of maternal obesogenicdiet exposure and metformin treatment during metabolic syndrome in pregnancy on FA composition and FA metabolism in the fetal compartment. However, this study has several limitations. Methodologically, the high calorie diet was provided only 5 weeks prior to pregnancy and throughout pregnancy (3 weeks) and thus, represents 'acute dietinduced obesity'. A longer HCAL diet-feeding period might better reflect the chronic obesity observed in humans. Because the normal and HCAL diets ( \pm metformin) were provided ad libitum we were unable to assess exact intakes. Also, maternal metformin treatment was modeled after rodent studies performed in the absence of pregnancy. Perhaps higher doses of metformin are required during pregnancy. Finally, these findings are difficult to extrapolate to humans, which is true for all studies using laboratory animals. Nevertheless, this model may provide us with a better understanding of the pathophysiological changes observed with maternal obesity/metabolic syndrome and the use of metformin for obesity-related metabolic syndrome during pregnancy.

It is important to note that maternal metformin treatment in humans does not compromise neurodevelopmental outcomes when measured in two year old children $[60,61]$. Our results show that metformin promotes preservation of fetal DHA (despite reduced maternal liver DHA) important for fetal/neonatal brain development. Recent studies by Salomaki and co-workers revealed that the fetal liver is an 
important target of maternal metformin and that protective effects on offspring were observed when dams were exposed to a high fat diet (vs. normal diet) prior to/during metformin treatment $[57,62]$. Our study differs in that a high fat, high sugar diet was administered to dams (prior to/during metformin treatment) rather than a regular diet [57] or a high fat diet [62]; the high fat, high sugar diet was chosen to better reflect the Western diet. Although our study was not designed to investigate the effects of a maternal high calorie diet ( \pm metformin) on long-term offspring outcomes, the data support the potential fetal programming effects of maternal obesity via changes in fetal fatty acid profiles and fetal liver IFNY concentrations, with reversal by maternal metformin administration. Both GDM and adult obesity are increasing $[3,4,63]$ and thus, represent widespread problems with potentially serious implications for mothers and their offspring. Therefore, future studies will focus on investigating the effects of metformin and other anti-diabetic and/or lipid normalizing strategies in the setting of obesity/metabolic syndrome during pregnancy on neonatal complications and long-term adverse metabolic consequences in the offspring. These studies would facilitate the development of interventions to mitigate the adverse effects of maternal obesity and metabolic syndrome on offspring health in the short- and long-terms.

\section{Conclusions}

Obesogenic diet consumption by pregnant mice led to changes in the fatty acid composition of maternal and fetal livers, including reductions in healthy PUFAs and antiinflammatory n3 FAs. In utero HCAL diet exposure increased liver IFN $\gamma$ concentrations without affecting maternal liver IFN $\gamma$ concentrations. While maternal metformin treatment did not significantly alter diet-induced maternal liver fatty acid changes, fetal exposure to metformin attenuated diet-induced changes in fetal liver DHA levels, antiinflammatory n3FAs and liver IFNY concentrations. Thus, maternal metformin might be beneficial for fetal/neonatal outcomes in the setting of maternal obesity and/or metabolic syndrome.

\section{Additional file}

Additional file 1: Table S1. Cytokine and chemokine profiles in maternal and fetal livers following normal and high calorie diets ( \pm metformin). (DOCX $21 \mathrm{~kb})$

\section{Acknowledgements}

The assistance of the staff of the Center for Comparative Physiology for taking care of the animals is acknowledged.

\section{Funding}

Research supported by The Feinstein Institute for Medical Research and The Katz Institute for Women's Health.

\section{Availability of data and materials}

The datasets supporting the conclusions of this article are included within the article and within the additional file. Please note: Data from this manuscript was presented, in part, at the $62^{\text {nd }}$ Annual Meeting of the Society for Reproductive Investigation (SRI) on March 27, 2015.

\section{Authors' contributions}

The present research was supported by the Feinstein Institute for Medical Research and the Katz Institute for Women's Health, Northwell Health. KH, $N D$, BR, and CNM designed and directed the study; $N D, X X, M G$, and CNM conducted the animal trial; $K H, X X, M G$, and PKC performed $\mathrm{PPCR}$, MSD assays, and western blot analyses; and $\mathrm{KH}$ and CNM performed the statistical analysis. All the authors participated in drafting and finalizing the manuscript. All authors read and approved the final manuscript.

\section{Competing interests}

The authors declare that they have no competing interests.

\section{Consent for publication}

All authors have reviewed the submitted manuscript and agree with its review and publication in Nutrition \& Metabolism.

\section{Ethics approval and consent to participate}

All animal experimentation was performed in accordance with the Public Health Service (PHS) Policy on Humane Care and Use of Laboratory Animals and euthanasia complied with the American Veterinary Medical Association (AVMA) Panel on Euthanasia. There was no consent to participate as no human subjects were involved in this study.

\section{Author details}

'Hofstra Northwell School of Medicine, Department of OB/GYN, Division of Maternal-Fetal Medicine, Manhasset, NY, USA. ${ }^{2}$ Elmezzi Graduate School of Molecular Medicine, Manhasset, NY, USA. ${ }^{3}$ Present Address: Jamaica Hospital Medical Center, Medisys Health Network, Jamaica, NY, USA. ${ }^{4}$ Winnie Palmer Hospital-Orlando Health, Orlando, FL, USA. ${ }^{5}$ The Feinstein Institute for Medical Research, The Center for Biomedical Sciences, Northwell Health, 350 Community Drive, Manhasset, NY 11030, USA.

Received: 29 June 2016 Accepted: 13 August 2016

Published online: 22 August 2016

\section{References}

1. Ogden $C L$, Carroll MD, Kit BK, Flegal KM. Prevalence of obesity in the United States, 2009-2010. NCHS Data Brief. 2012;1-8

2. Danaei G, Finucane MM, Lu Y, Singh GM, Cowan MJ, Paciorek CJ, Lin JK, Farzadfar F, Khang YH, Stevens GA, Rao M, Ali MK, Riley LM, Robinson CA, Ezzati M. National, regional, and global trends in fasting plasma glucose and diabetes prevalence since 1980. systematic analysis of health examination surveys and epidemiological studies with 370 country-years and 2.7 million participants. Lancet. 2011;378:31-40.

3. Finucane MM, Stevens GA, Cowan MJ, Danaei G, Lin JK, Paciorek CJ, Singh GM, Gutierrez HR, Lu Y, Bahalim AN, Farzadfar F, Riley LM, Ezzati M. National, regional, and global trends in body-mass index since 1980: systematic analysis of health examination surveys and epidemiological studies with 960 countryyears and 9.1 million participants. Lancet. 2011;377:557-67.

4. Flegal KM, Kruszon-Moran D, Carroll MD, Fryar CD, Ogden CL. Trends in obesity among adults in the United States, 2005 to 2014. JAMA. 2016;315:2284-91.

5. Ogden $\mathrm{CL}$, Carroll MD, Lawman HG, Fryar CD, Kruszon-Moran D, Kit BK, Flegal KM. Trends in obesity prevalence among children and adolescents in the United States, 1988-1994 through 2013-2014. JAMA. 2016;315:2292-9.

6. Ramsay JE, Ferrell WR, Crawford L, Wallace AM, Greer IA, Sattar N. Maternal obesity is associated with dysregulation of metabolic, vascular, and inflammatory pathways. J Clin Endocrinol Metab. 2002;87:4231-7.

7. Nelson SM, Matthews P, Poston L. Maternal metabolism and obesity: modifiable determinants of pregnancy outcome. Hum Reprod Update. 2010;16:255-75.

8. Ray JG, Diamond P, Singh G, Bell CM. Brief overview of maternal triglycerides as a risk factor for pre-eclampsia. BJOG. 2006;113:379-86.

9. King JC. Maternal obesity, metabolism, and pregnancy outcomes. Annu Rev Nutr. 2006;26:271-91. 
10. Bellamy L, Casas JP, Hingorani AD, Williams D. Type 2 diabetes mellitus after gestational diabetes: a systematic review and meta-analysis. Lancet. 2009;373:1773-9

11. England L, Dietz PM, Njoroge T, Callaghan WM, Bruce C, Buus RM, Williamson DF. Preventing type 2 diabetes: public health implications for women with a history of gestational diabetes mellitus. Am J Obstet Gynecol. 2009;200:365-8.

12. Sullivan SD, Umans JG, Ratner R. Gestational diabetes: implications for cardiovascular health. Curr Diab Rep. 2012;12:43-52.

13. Reece EA. The fetal and maternal consequences of gestational diabetes mellitus. J Matern Fetal Neonatal Med. 2010;23:199-203.

14. Choi GY, Tosh DN, Garg A, Mansano R, Ross MG, Desai M. Gender-specific programmed hepatic lipid dysregulation in intrauterine growth-restricted offspring. Am J Obstet Gynecol. 2007;196:477.

15. Bruce KD, Cagampang FR, Argenton M, Zhang J, Ethirajan PL, Burdge GC, Bateman AC, Clough GF, Poston L, Hanson MA, McConnell JM, Byrne CD. Maternal high-fat feeding primes steatohepatitis in adult mice offspring, involving mitochondrial dysfunction and altered lipogenesis gene expression. Hepatology. 2009;50:1796-808.

16. Srinivasan M, Katewa SD, Palaniyappan A, Pandya JD, Patel MS. Maternal high-fat diet consumption results in fetal malprogramming predisposing to the onset of metabolic syndrome-like phenotype in adulthood. Am J Physiol Endocrinol Metab. 2006;291:E792-9.

17. Szostak-Wegierek D. Intrauterine nutrition: long-term consequences for vascular health. Int J Womens Health. 2014;6:647-56. doi:10.2147/IJWH. S48751.eCollection@2014.: 647-656.

18. Practice Bulletin No. 137. Gestational diabetes mellitus. Obstet Gynecol. 2013;122:406-16.

19. Giugliano D, De RN, Di MG, Marfella R, Acampora R, Buoninconti R, D'Onofrio F. Metformin improves glucose, lipid metabolism, and reduces blood pressure in hypertensive, obese women. Diabetes Care. 1993;16:1387-90.

20. Anurag P, Anuradha CV. Metformin improves lipid metabolism and attenuates lipid peroxidation in high fructose-fed rats. Diabetes Obes Metab. 2002:4:36-42.

21. Lin HZ, Yang SQ, Chuckaree C, Kuhajda F, Ronnet G, Diehl AM. Metformin reverses fatty liver disease in obese, leptin-deficient mice. Nat Med. 2000;6:998-1003.

22. Charles B, Norris R, Xiao X, Hague W. Population pharmacokinetics of metformin in late pregnancy. Ther Drug Monit. 2006;28:67-72.

23. Nanovskaya TN, Nekhayeva IA, Patrikeeva SL, Hankins GD, Ahmed MS. Transfer of metformin across the dually perfused human placental lobule. Am J Obstet Gynecol. 2006;195:1081-5.

24. Desai N, Roman A, Rochelson B, Gupta M, Xue X, Chatterjee PK, Tam TH, Metz CN. Maternal metformin treatment decreases fetal inflammation in a rat model of obesity and metabolic syndrome. Am J Obstet Gynecol. 2013;209:136-9.

25. Holemans K, Caluwaerts S, Poston L, Van Assche FA. Diet-induced obesity in the rat: a model for gestational diabetes mellitus. Am J Obstet Gynecol. 2004; 190:858-65.

26. Folch J, Lees M, Sloane Stanley GH. A simple method for the isolation and purification of total lipides from animal tissues. J Biol Chem. 1957;226:497-509.

27. Morrison WR, Smith IM. Preparation of fatty acid methyl esters and dimethylacetals from lipids with boron fluoride-methanol. J Lipid Res. 1964;5:600-8.

28. Gupta M, Solanki MH, Chatterjee PK, Xue X, Roman A, Desai N, Rochelson B, Metz CN. Maternal magnesium deficiency in mice leads to maternal metabolic dysfunction and altered lipid metabolism with fetal growth restriction. Mol Med. 2014;20:332-40.

29. Dowling O, Chatterjee PK, Gupta M, Tam Tam HB, Xue X, Lewis D, Rochelson B, Metz CN. Magnesium sulfate reduces bacterial LPS-induced inflammation at the maternal-fetal interface. Placenta. 2012;33:392-8.

30. Cikos S, Bukovska A, Koppel J. Relative quantification of mRNA: comparison of methods currently used for real-time PCR data analysis. BMC Mol Biol. 2007:8:113-27.

31. Roman A, Desai N, Rochelson B, Gupta M, Solanki M, Xue X, Chatterjee PK, Metz CN. Maternal magnesium supplementation reduces intrauterine growth restriction and suppresses inflammation in a rat model. Am J Obstet Gynecol. 2013;208:383-7.

32. Solanki MH, Chatterjee PK, Gupta M, Xue X, Plagov A, Metz MH, Mintz R, Singhal PC, Metz CN. Magnesium protects against cisplatin-induced acute kidney injury by regulating platinum accumulation. Am J Physiol Renal Physiol. 2014;307:F369-84.
33. Innis SM. Perinatal biochemistry and physiology of long-chain polyunsaturated fatty acids. J Pediatr. 2003;143:S1-8.

34. Coti BP, O'Kusky JR, Innis SM. Maternal dietary (n-3) fatty acid deficiency alters neurogenesis in the embryonic rat brain. J Nutr. 2006;136:1570-5.

35. Westermeier F, Saez PJ, Villalobos-Labra R, Sobrevia L, and Farias-Jofre M. Programming of fetal insulin resistance in pregnancies with maternal obesity by ER stress and inflammation. Biomed Res Int. 2014;917672. doi: 10.1155/2014/917672

36. Horton JD, Goldstein JL, Brown MS. SREBPs: activators of the complete program of cholesterol and fatty acid synthesis in the liver. J Clin Invest. 2002;109:1125-31.

37. Horton JD, Shah NA, Warrington JA, Anderson NN, Park SW, Brown MS, Goldstein JL. Combined analysis of oligonucleotide microarray data from transgenic and knockout mice identifies direct SREBP target genes. Proc Natl Acad Sci U S A. 2003:100:12027-32.

38. Shimano H, Horton JD, Shimomura I, Hammer RE, Brown MS, Goldstein JL. Isoform 1c of sterol regulatory element binding protein is less active than isoform 1a in livers of transgenic mice and in cultured cells. J Clin Invest. 1997;99:846-54

39. Wiernsperger N. Hepatic function and the cardiometabolic syndrome. Diabetes Metab Syndr Obes. 2013;6:379-88. doi:10.2147/DMSO.S51145.

40. Lewis GF, Carpentier A, Adeli K, Giacca A. Disordered fat storage and mobilization in the pathogenesis of insulin resistance and type 2 diabetes. Endocr Rev. 2002;23:201-29.

41. Heerwagen MJ, Miller MR, Barbour LA, Friedman JE. Maternal obesity and fetal metabolic programming: a fertile epigenetic soil. Am J Physiol Regul Integr Comp Physiol. 2010;299:R711-22.

42. McCurdy CE, Bishop JM, Williams SM, Grayson BE, Smith MS, Friedman JE, Grove KL. Maternal high-fat diet triggers lipotoxicity in the fetal livers of nonhuman primates. J Clin Invest. 2009;119:323-35.

43. Kaneda M, Kashiwamura S, Ueda H, Sawada K, Sugihara A, Terada N, KimuraShimmyo A, Fukuda Y, Shimoyama T, Okamura H. Inflammatory liver steatosis caused by IL-12 and IL-18. J Interferon Cytokine Res. 2003;23:155-62.

44. Marchesini G, Brizi M, Morselli-Labate AM, Bianchi G, Bugianesi E, McCullough AJ, Forlani G, Melchionda N. Association of nonalcoholic fatty liver disease with insulin resistance. Am J Med. 1999:107:450-5.

45. Crowther CA, Hiller JE, Moss JR, MCPhee AJ, Jeffries WS, Robinson JS. Effect of treatment of gestational diabetes mellitus on pregnancy outcomes. N Engl J Med. 2005;352:2477-86.

46. Helvaci MR, Kaya H, Borazan A, Ozer C, Seyhanli M, Yalcin A. Metformin and parameters of physical health. Intern Med. 2008;47:697-703.

47. Smith AC, Mullen KL, Junkin KA, Nickerson J, Chabowski A, Bonen A, Dyck DJ. Metformin and exercise reduce muscle FAT/CD36 and lipid accumulation and blunt the progression of high-fat diet-induced hyperglycemia. Am J Physiol Endocrinol Metab. 2007;293:E172-81.

48. Coetzee EJ, Jackson WP. Metformin in management of pregnant insulinindependent diabetics. Diabetologia. 1979;16:241-5.

49. Rowan JA, Hague WM, Gao W, Battin MR, Moore MP. Metformin versus insulin for the treatment of gestational diabetes. $N$ Engl J Med. 2008;358:2003-15.

50. Charlton RA, Klungsoyr K, Neville AJ, Jordan S, Pierini A, de Jong-van den Berg LT, Bos HJ, Puccini A, Engeland A, Gini R, Davies G, Thayer D, Hansen AV, Morgan M, Wang H, McGrogan A, Nybo Andersen AM, Dolk H, Garne E. Prescribing of antidiabetic medicines before, during and after pregnancy: a study in seven European regions. PLOS ONE. 2016:11:e0155737.

51. Nicholson W, Bolen S, Witkop CT, Neale D, Wilson L, Bass E. Benefits and risks of oral diabetes agents compared with insulin in women with gestational diabetes: a systematic review. Obstet Gynecol. 2009;113:193-205.

52. Zhu B, Zhang L, Fan YY, Wang L, Li XG, Liu T, Cao YS, Zhao ZG. Metformin versus insulin in gestational diabetes mellitus: a meta-analysis of randomized clinical trials. Ir J Med Sci. 2016;185:371-81.

53. Barrett $\mathrm{HL}$, Dekker NM, Jones L, O'Rourke P, Lust K, Gatford KL, De Blasio MJ, Coat S, Owens JA, Hague WM, Mclntyre HD, Callaway L, Rowan J. Determinants of maternal triglycerides in women with gestational diabetes mellitus in the Metformin in Gestational Diabetes (MiG) study. Diabetes Care. 2013:36:1941-6.

54. Kita Y, Takamura T, Misu H, Ota T, Kurita S, Takeshita Y, Uno M, MatsuzawaNagata N, Kato K, Ando H, Fujimura A, Hayashi K, Kimura T, Ni Y, Otoda T, Miyamoto K, Zen Y, Nakanuma Y, Kaneko S. Metformin prevents and reverses inflammation in a non-diabetic mouse model of nonalcoholic steatohepatitis. PLoS ONE. 2012;7:e43056. 
55. Algire C, Amrein L, Zakikhani M, Panasci L, Pollak M. Metformin blocks the stimulative effect of a high-energy diet on colon carcinoma growth in vivo and is associated with reduced expression of fatty acid synthase. Endocr Relat Cancer. 2010;17:351-60.

56. Zawiejska A, Wender-Ozegowska E, Grewling-Szmit K, Brazert M, Brazert J. Short-term antidiabetic treatment with insulin or metformin has a similar impact on the components of metabolic syndrome in women with gestational diabetes mellitus requiring antidiabetic agents. Results of a prospective, randomised study. J Physiol Pharmacol. 2016;67:227-33.

57. Salomaki $H$, Vahatalo LH, Laurila K, Jappinen NT, Penttinen AM, Ailanen L, llyasizadeh J, Pesonen U, Koulu M. Prenatal metformin exposure in mice programs the metabolic phenotype of the offspring during a high fat diet at adulthood. PLoS ONE. 2013:8:e56594.

58. Koh SJ, Kim JM, Kim IK, Ko SH, Kim JS. Anti-inflammatory mechanism of metformin and its effects in intestinal inflammation and colitis-associated colon cancer. J Gastroenterol Hepatol. 2014;29:502-10.

59. Isoda K, Young JL, Zirlik A, MacFarlane LA, Tsuboi N, Gerdes N, Schonbeck U, Libby P. Metformin inhibits proinflammatory responses and nuclear factorkappaB in human vascular wall cells. Arterioscler Thromb Vasc Biol. 2006;26:611-7.

60. Tertti K, Eskola E, Ronnemaa T, Haataja L. Neurodevelopment of two-yearold children exposed to metformin and insulin in gestational diabetes mellitus. J Dev Behav Pediatr. 2015;36:752-7.

61. Wouldes TA, Battin M, Coat S, Rush EC, Haque WM, Rowan JA. Neurodevelopmental outcome at 2 years in offspring of women randomised to metformin or insulin treatment for gestational diabetes. Arch Dis Child Fetal Neonatal Ed. 2016. fetalneonatal-309602

62. Salomäki $H$, Heinäniemi $M$, Vähätalo LH, Ailanen L, Eerola K, Ruohonen ST, Pesonen $\mathrm{U}$, Koulu M. Prenatal metformin exposure in a maternal high fat diet mouse model alters the transcriptome and modifies the metabolic responses of the offspring. PLoS One. 2014;9:e115778, doi:10.1371/journal.pone.0115778.

63. Ferrara A. Increasing prevalence of gestational diabetes mellitus. a public health perspective. Diabetes Care. 2007;30 Suppl 2:S141-6.

\section{Submit your next manuscript to BioMed Central and we will help you at every step:}

- We accept pre-submission inquiries

- Our selector tool helps you to find the most relevant journal

- We provide round the clock customer support

- Convenient online submission

- Thorough peer review

- Inclusion in PubMed and all major indexing services

- Maximum visibility for your research

Submit your manuscript at www.biomedcentral.com/submit

) Biomed Central 